\title{
ESTIMASI PARAMETER MODEL FUNGSI ALIH ORDE 4 PADA ROL PENGUMPAN SISTEM TRANSPORTASI WEB MATERIAL BERBASIS FORGETTING FACTOR DENGAN MATLAB 7.04
}

\author{
Yaya Finayani ${ }^{1)}$, Muhammad Alhan ${ }^{2)}$ \\ ${ }^{1), 2)}$ Teknik Elektro, Politeknik Pratama Mulia, Surakarta 57149, Indonesia \\ email: yyfinayani@yahoo.com
}

\begin{abstract}
Web Materials Transport system appears in variety of industrial applications such as paper and plastics industries. The main part of web transport system is unwind roll section. The dynamic model for unwind roll section is derived from the Newton's laws, the Hooke's law and conservations of mass principle. This model gives a relationship between web tension output and torque input. Futhermore this relationship is expressed in transfer function form. This transfer function contains a phisical time-varying parameter namely the radius of the unwind roll. Usually before designing control system, a model parameter estimation is needed. This on-line estimation problem is investigated in this paper using RLS (recursive least square) method with forgetting factor. The estimation needs data in the form of discrete and the initial value covariance matrix diagonal $(P)$. This research uses discrete $\mathrm{ZOH}$ method with sampling period $T=0.4 \mathrm{sec} ; 0.35 \mathrm{sec} ; 0.3 \mathrm{sec} ; 0.25 \mathrm{sec} ; 0.2 \mathrm{sec}$ for convert transfer function from s-domain to $z$-domain. Parameters estimation with mean square error (MSE) in the range $2 \times 10^{-5} \leq M S E \leq$ $3 \times 10^{-5}$ are obtained using initial value covariance matrix diagonal $P$ in the range $10^{2} \leq P \leq 10^{8}$ using forgetting factor 0.95 .
\end{abstract}

Keywords: forgetting factor, recursive least square, web material, transport system, RLS

Sistem transportasi web material banyak dijumpai pada industri kertas dan plastik. Bagian utama sistem transportasi web material adalah bagian rol pengumpan. Model dinamik rol pengumpan dijabarkan dari hukum Newton, hukum Hooke dan hukum konservasi massa. Model ini menyatakan hubungan antara gaya tegang keluaran web terhadap masukan gaya putar. Hubungan ini diberikan dalam bentuk fungsi alih yang ternyata mengandung parameter fisik plant yang berubah terhadap waktu yaitu radius rol pengumpan. Biasanya sebelum perancangan pengendalian diperlukan estimasi parameter model. Problem estimasi parameter model secara on-line ini diteliti dengan menggunakan metode RLS (recursive least square) berbasis faktor pembobot data yang dinamakan forgetting factor. Estimasi parameter model memerlukan data dalam bentuk diskrit dan inisialisasi awal diagonal matrik kovarian (P). Penelitian ini menggunakan metode diskritisasi zero order hold $(\mathrm{ZOH})$ dengan periode cuplikan 0,4 detik; 0,35 detik; 0,3 detik; 0,25 detik dan 0,2 detik untuk mengubah fungsi alih bidang-s ke bidang-z. Estimasi akan konvergen bila digunakan inisialisasi awal diagonal matrik kovarian sebesar $10^{2} \leq P \leq 10^{8}$ dengan kisaran MSE (mean square error) sebesar $2 \times 10^{-5} \leq \mathrm{MSE} \leq 3 \times 10^{-5}$ dengan forgetting factor 0,95 .

Kata kunci : forgetting factor, recursive least square, web material, transport system, RLS

\section{PENDAHULUAN}

Web adalah sebidang material yang diproses dan dihasilkan secara kontinu dalam suati proses di industri kertas dan plastik [1]. Adapun sistem transportasi web material berhubungan dengan aliran web selama proses produksi, contoh sistem transportasi web yaitu proses pelapisan aluminium foil pada plastik untuk pembungkus makanan, proses pengeringan pembuatan kertas. Web harus melalui beberapa bagian pengolahan dari proses yang berkelanjutan secara kontinu, salah satunya yaitu rol pengumpan (Gambar 1) [2]. 


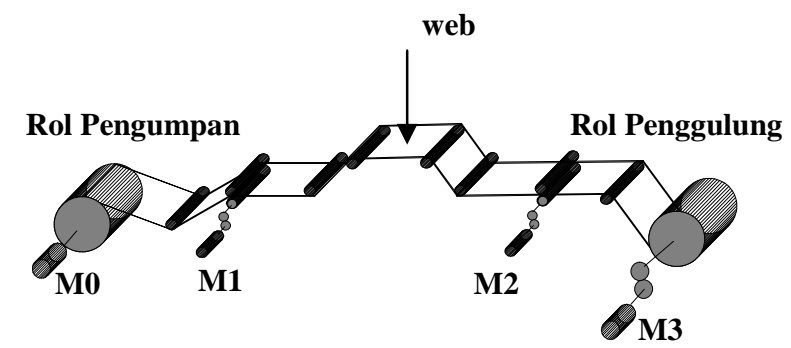

\section{Gambar 1. Sistem Transportasi Web Material}

Rol pengumpan merupakan bagian awal dari sistem transportasi web material dan berakhir pada baian rol penggulung. Sistem transportasi web material terdiri dari rol yang digerakkan oleh rangkaian penggerak motor (M0, M1, M2, M3) dengan menggunakan motor DC.

Karakteristik dinamis serta analisis suatu sistem dapat diketahui melalui model matematik [3], sehingga untuk mengetahui karakteristik bagian rol pengumpan sistem transportasi web material diperlukan model matematik. Model matematik dari sistem transportasi web material diperoleh dari penjabaran hukum Newton tentang gerak, hukum Hooke tentang elastisitas, hukum Konservasi Massa tentang volume atur, serta hukum Coulomb dari rentangan web diantara sepasang rol yang berurutan (Gambar 2) [4], model yang diperoleh berupa model persamaan dinamik gaya tegang.

Menerapkan hukum Hooke pada Gambar 2, dengan $L_{1}$ adalah panjang sebelum mendapatkan stress (unstretched state) dan $\mathrm{L}_{2}$ panjang setelah mendapatkan stress (stretched state) diperoleh persamaan:

$\varepsilon=\frac{L_{2}-L_{1}}{L_{1}}$

Hukum Konservasi Massa dari Gambar 2,

$\frac{\rho_{2} A}{\rho_{1} A}=\frac{L_{1}}{L_{2}}=\frac{1}{1+\varepsilon}$

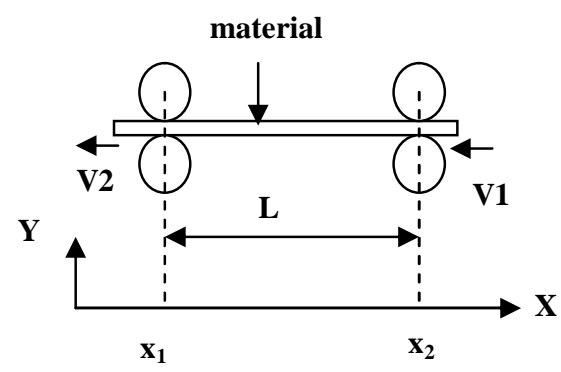

Keterangan:

Gambar 2. Sepasang rol sistem transportasi web
$\mathrm{L} \quad=$ jarak antara rol
$\mathrm{V} 1=$ kecepatan aliran web sebelum mendapat stress
V2 = kecepatan aliran web setelah mendapat stress

Asumsi Gambar 2 bahwa strain adalah uniform, akan diperoleh persamaan dari hukum konservasi massa: 
$m=\int_{x_{1}}^{x_{2}} \rho(x, t) A(x, t) d x=L \rho_{2}(t) A_{2}(t)$.

Gaya tegang antara sepasang rol Gambar 2, dengan mengaplikasikan persamaan kontinuitas [4],

$\frac{\partial \rho}{\partial t}+\frac{\partial(\rho V)}{\partial x}=0$

$\int_{v} \frac{\partial}{\partial t}\left(\frac{1}{1+\varepsilon}\right) d V=-\int_{v} \frac{\partial}{\partial x}\left(\frac{V}{1+\varepsilon}\right) d V$

$\frac{\partial}{\partial t} \int_{x_{1}}^{x_{2}} \frac{1}{1+\varepsilon(x, t)}=-\int_{x_{1}}^{x_{2}} \frac{\partial}{\partial x}\left[\frac{V(x, t)}{1+\varepsilon(x, t)}\right]$

$L \frac{d}{d t}\left[\frac{1}{1+\varepsilon_{2}}\right]=\frac{V_{1}(t)}{1+\varepsilon_{1}(t)}-\frac{V_{2}(t)}{1+\varepsilon_{2}(t)}$.

dengan,

$\mathrm{V}=$ kecepatan web

$\rho=$ densitas

$\varepsilon \quad=$ strain

asumsi $\varepsilon$ bernilai kecil, maka diperoleh

$\dot{\varepsilon}_{2}=\frac{1}{L}\left[\varepsilon_{1}(t) V_{1}(t)-\varepsilon_{2}(t) V_{2}(t)+V_{2}(t)-V_{1}(t)\right]$

Dengan mengaplikasikan hukum Hooke pada persamaan (7) diperoleh,

$\dot{T}_{2}=\frac{1}{L}\left[A E\left(V_{2}-V_{1}\right)+V_{1} T_{1}-V_{2} T_{2}\right]$

Persamaan (8) dapat ditulis secara umum sebagai persamaan dinamik gaya tegang web :

$L \dot{T}_{i}=A_{i} E_{i}\left(V_{i}-V_{i-1}\right)+V_{i-1} T_{i-1}-V_{i} T_{i}$

Dengan,

$\mathrm{L}_{\mathrm{i}} \quad=$ jarak antara dua rol yang berururan ke-i

$\mathrm{T}_{\mathrm{i}} \quad$ = gaya tegang ke- $\mathrm{i}$

$A_{i}=$ luas permukaan webmaterial

$\mathrm{E}_{\mathrm{i}} \quad=$ modulus elastisitas web material ke- $\mathrm{i}$

\section{Metode Penelitian}

Model sistem transportasi web terdiri 4 bagian [1]:

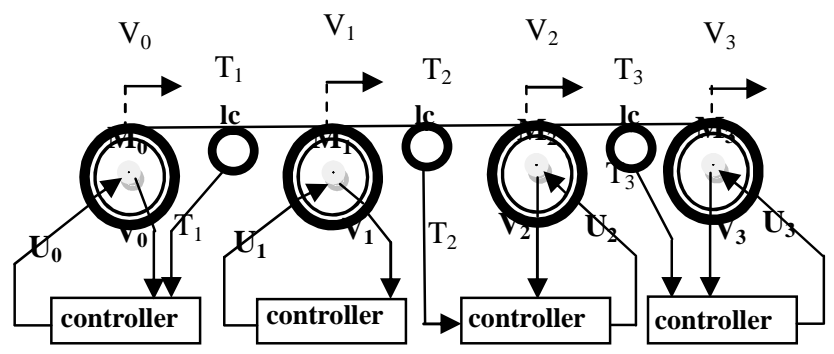

Gambar 3. Model Sistem Transportasi Web Material 
Keterangan,

$M_{0}, M_{1}, M_{2}, M_{3} \quad=$ motor penggerak tiap rol

$\mathrm{U}_{0}, \mathrm{U}_{1}, \mathrm{U}_{2}, \mathrm{U}_{3} \quad$ = masukan gaya putar tiap rol

$\mathrm{V}_{0}, \mathrm{~V}_{1}, \mathrm{~V}_{2}, \mathrm{~V}_{3} \quad=$ kecepatan linear tiap rol

$\mathrm{T}_{1}, \mathrm{~T}_{2}, \mathrm{~T}_{3} \quad$ = keluaran gaya tegang

Ic $\quad=$ load cell

controller = bagian pengendali

Dengan menerapkan persamaan dinamik gaya tegang (9) diperoleh persamaan tiap bagian rol pengumpan $\left(\mathrm{M}_{0}\right)$, bagian master speed $\left(\mathrm{M}_{1}\right)$, bagian proses $\left(\mathrm{M}_{2}\right)$ dan bagian rol penggulung $\left(\mathrm{M}_{3}\right)$,

a. Bagian rol pengumpan,

$L_{1} \dot{T}_{1}=A_{1} E_{1}\left(V_{1}-V_{0}\right)+V_{0} T_{0}-V_{1} T_{1}$

b. Bagian master speed (persamaan dinamik kecepatan)

$\frac{J_{1}}{R_{1}} \dot{V}_{1}=\left(T_{2}-T_{1}\right) R_{1}+n_{1} U_{1}-\frac{b_{f 1}}{R_{1}} V_{1}$

dengan, $J_{1}=$ inersia master speed

$\mathrm{R}_{1}=$ radius master speed

$\mathrm{b}_{\mathrm{f} 1}=$ koefisien friksi

$\mathrm{n}=$ rasio gear

C. Bagian proses

$L_{2} \dot{T}_{2}=A_{2} E_{2}\left(V_{2}-V_{1}\right)+V_{1} T_{1}-V_{2} T_{2}$

d. Bagian rol penggulung

$L_{3} \dot{T}_{3}=A_{3} E_{3}\left(V_{3}-V_{2}\right)+V_{2} T_{2}-V_{3} T_{3}$

Persamaan (10), (11), (12), (13) disusun dalam bentuk persamaan ruang keadaan dengan asumsi [5] hubungan statik motor DC adalah,

$\omega=\frac{1}{k_{t}} U$

Dengan,

$\omega=$ kecepatan sudut

$\mathrm{k}_{\mathrm{t}} \quad=$ konstanta gaya putar

$\mathrm{U}=$ masukan gaya putar

Diperoleh persamaan keadaan,

$\dot{T}_{1}=-c_{1} \frac{R_{0}(t)}{k t} U_{0}+c_{1} \frac{R_{1}}{k t} U_{1}-\frac{V_{1}}{L_{1}} T_{1}$

$\dot{T}_{2}=-c_{2} \frac{R_{1}}{k t} U_{1}+c_{2} \frac{R_{2}}{k t} U_{2}+\frac{V_{1}}{L_{2}} T_{1}-\frac{V_{2}}{L_{2}} T_{2}$

$\dot{T}_{3}=-c_{3} \frac{R_{2}}{k t} U_{2}+c_{3} \frac{R_{3}(t)}{k t} U_{3}+\frac{V_{2}}{L_{3}} T_{2}-\frac{V_{3}}{L_{3}} T_{3}$

$\dot{\omega}_{1}=\frac{n_{1}}{J_{1}} U_{1}-\frac{R_{1}}{J_{1}} T_{1}+\frac{R_{1}}{J_{1}} T_{2}-\frac{b_{f 1}}{J_{1}} \omega_{1}$

Jika diubah ke bentuk state space:

$x=A x+B u$

$y(t)=C x(t)$ 


\section{Dengan,}

$x=\left[\begin{array}{llll}T_{1} & T_{2} & T_{3} & \omega_{1}\end{array}\right]^{T}, u=\left[\begin{array}{llll}U_{0} & U_{1} & U_{2} & U_{3}\end{array}\right]^{T}$

$A=\left[\begin{array}{cccc}-\frac{V_{1}}{L_{1}} & 0 & 0 & 0 \\ \frac{V_{1}}{L_{2}} & -\frac{V_{2}}{L_{2}} & 0 & 0 \\ 0 & \frac{V_{2}}{L_{3}} & -\frac{V_{3}}{L_{3}} & 0 \\ -\frac{R_{1}}{J_{1}} & \frac{R_{1}}{J_{1}} & 0 & -\frac{b_{f 1}}{J_{1}}\end{array}\right]$

$B=\left[\begin{array}{cccc}-c_{1} \frac{R_{0}(t)}{k t} & c_{1} \frac{R_{1}}{k t} & 0 & 0 \\ 0 & -c_{2} \frac{R_{1}}{k t} & c_{2} \frac{R_{2}}{k t} & 0 \\ 0 & 0 & -c_{3} \frac{R_{2}}{k t} & c_{3} \frac{R_{3}(t)}{k t} \\ 0 & \frac{n_{1}}{J_{1}} & 0 & 0\end{array}\right] \ldots \ldots(19)$

$C=\left[\begin{array}{llll}1 & 0 & 0 & 0\end{array}\right]$

Dengan, $c_{i}=\frac{A E}{L_{i}}$ dengan $\mathrm{i}=1,2,3$

Fungsi alih bagian rol pengumpan dalam bidang s diperoleh dari penjabaran persamaan (16) dan (17),

$\frac{T_{1}(s)}{U_{0}(s)}=\frac{q_{3} s^{3}+q_{3} s^{2}+q_{1} s+q_{0}}{p_{4} s^{4}+p_{3} s^{3}+p_{2} s^{2}+p_{1} s+p_{0}}$

Dengan,

$q_{0}=\left[\frac{V_{2}}{L_{2}} \frac{V_{3}}{L_{3}} \frac{b_{f 1}}{J_{1}}\right]\left(-c_{1} \frac{R_{0}(t)}{k t}\right)$

$q_{1}=\left[\frac{V_{3}}{L_{3}} \frac{b_{f 1}}{J_{1}}+\frac{V_{2}}{L_{2}} \frac{V_{3}}{L_{3}}+\frac{V_{2}}{L_{2}} \frac{b_{f 1}}{J_{1}}\right]\left(-c_{1} \frac{R_{0}(t)}{k t}\right)$

$q_{2}=\left[\frac{b_{f 1}}{J_{1}}+\frac{V_{3}}{L_{3}}+\frac{V_{2}}{L_{2}}\right]\left(-c_{1} \frac{R_{0}(t)}{k t}\right)$

$q_{3}=\left(-c_{1} \frac{R_{0}(t)}{k t}\right)$

$p_{0}=\left[\frac{V_{1}}{L_{1}} \frac{V_{2}}{L_{2}} \frac{V_{3}}{L_{3}} \frac{b_{f 1}}{J_{1}}\right]$

$p_{1}=\left[\frac{V_{2}}{L_{2}} \frac{V_{3}}{L_{3}} \frac{b_{f 1}}{J_{1}}+\frac{V_{1}}{L_{1}} \frac{V_{3}}{L_{3}} \frac{b_{f 1}}{J_{1}}+\frac{V_{1}}{L_{1}} \frac{V_{2}}{L_{2}} \frac{b_{f 1}}{J_{1}}+\frac{V_{1}}{L_{1}} \frac{V_{2}}{L_{2}} \frac{V_{3}}{L_{3}}\right]$

$p_{2}=\left[\frac{V_{3}}{L_{3}} \frac{b_{f 1}}{J_{1}}+\frac{V_{2}}{L_{2}} \frac{b_{f 1}}{J_{1}}+\frac{V_{2}}{L_{2}} \frac{V_{3}}{L_{3}}+\frac{V_{1}}{L_{1}} \frac{V_{3}}{L_{3}}+\frac{V_{1}}{L_{1}} \frac{V_{2}}{L_{2}}\right]$ 
$p_{3}=\left[\frac{b_{f 1}}{J_{1}}+\frac{V_{3}}{L_{3}}+\frac{V_{2}}{L_{2}}+\frac{V_{1}}{L_{1}}\right] ; p_{4}=1$

Data parameter yang digunakan untuk persamaan (21) [6] ditunjukkan Tabel 1,

\section{Tabel 1. Data Parameter Sistem Transportasi Web}

\begin{tabular}{|c|c|c|c|c|c|c|}
\hline $\mathrm{V}_{0,1,2,3}$ & $\mathrm{~L}_{1}$ & $\mathrm{~L}_{2}$ & $\mathrm{~L}_{3}$ & $\mathrm{k}_{\mathrm{t}}$ & $\mathrm{J}_{1}$ & $\mathrm{AE}$ \\
\hline$(\mathrm{fpm})$ & $(\mathrm{ft})$ & $(\mathrm{ft})$ & $(\mathrm{ft})$ & - & $\begin{array}{c}(\mathrm{lb} \\
- \\
\mathrm{ft}^{2}\end{array}$ & $(\mathrm{lbf})$ \\
\hline 1000 & 20 & 33 & 67 & 1 & 2 & $\begin{array}{c}200 \\
0\end{array}$ \\
\hline $\mathrm{n}_{1}$ & $\mathrm{R}_{0}$ & $\mathrm{R}_{1}$ & $\mathrm{R}_{2}$ & $\mathrm{R}_{3}$ & $\mathrm{H}$ & \\
\hline- & $(\mathrm{ft})$ & $(\mathrm{ft})$ & $(\mathrm{ft})$ & $(\mathrm{ft})$ & \multicolumn{2}{|c|}{$(\mathrm{ft})$} \\
\hline 1 & 1,25 & 0,339 & 0,339 & 0,67 & 0,0000656 \\
\hline
\end{tabular}

Subtitusikan Tabel 1 ke persamaan (21), diperoleh

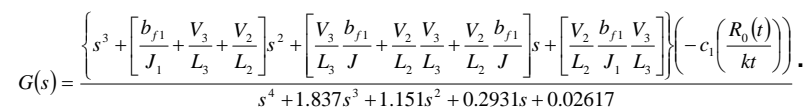

Persamaan (24) untuk selanjutnya mewakili plant sesungguhnya yaitu bagian rol pengumpan sistem transportasi web material.

Persamaan (24) terdapat parameter fungsi alih alih yang berubah terhadap waktu (time varying) yaitu radius rol pengumpan $R_{0}(t)$ yang berkurang panjang radius selama proses transportasi web material.

Proses estimasi parameter bertujuan untuk menafsirkan parameter-parameter plant dengan dasar pengukuran masukan dan keluaran dinyatakan dalam suatu model.

Proses estimasi parameter diawali dengan proses diskritisasi menggunakan metode $\mathrm{ZOH}$ (zero order hold) dengan periode pencuplikan 0,4 detik; 0,35 detik; 0,3 detik; 0,25 detik dan 0,2 detik untuk mengubah fungsi alih bidang-s ke bidang-z.

$$
\begin{aligned}
& H(z)=\left(1-z^{-1}\right) Z\left[L_{p}^{-1} \frac{G(s)}{s}\right] . \\
& H(z)=\frac{b_{1} z^{-1}+b_{2} z^{-2}+b_{3} z^{-3}+b_{4} z^{-4}}{1+a_{1} z^{-1}+a_{2} z^{-2}+a_{3} z^{-3}+a_{4} z^{-4}} \ldots . .
\end{aligned}
$$

Dari persamaan (26) terlihat bahwa ada 8 parameter fungsi alih yang akan diestimasi yaitu $a_{1}$, $a_{2}, a_{3}, a_{4}, b_{1}, b_{2}, b_{3}, b_{4}$.

Metode yang digunakan untuk memperoleh hasil estimasi parameter yang secara on-line bisa mengikuti perubahan radius rol pengumpan $R_{0}(t)$ yaitu dengan menggunakan metode $R L S$ (recursive least square) berbasis faktor pembobot data yang dinamakan forgetting factor.

Metode RLS, model regresi liner diasumsikan [7]

$\hat{y}(t)=\varphi^{T}(t) \theta$

Dengan estimasi least square, diperoleh

$\hat{\theta}(t)=\hat{\theta}(t-1)+P(t) \varphi(t)\left(y(t)-\varphi^{T}(t) \hat{\theta}(t-1)\right) \ldots$. 
$P(t)=P(t-1)-\frac{P(t-1) \varphi^{T}(t) \varphi^{T}(t) P(t-1)}{1+\varphi(t) P(t-1) \varphi^{T}(t)} \ldots$.

Dengan,

$\varphi^{T} \quad=$ vektor regresi

$\theta \quad=$ vektor parameter

$P(t)=$ matrik kovarian

$y(t)=$ keluaran

Jika bentuk sistem time-varying,

$y(t)=\varphi^{T}(t) \theta_{0}(t)+e(t)$

Dengan, $\theta_{0}(t)=$ nektor parameter time-varying, kriteria leasr square,

$J=\sum_{s=t-N}^{t} \lambda^{t-s}(y(s)-\hat{y}(s))^{2}$

Dengan, $\lambda=$ forgetting factor bernilai $(0<\lambda \leq 1)$, sehingga diperoleh rumus,

$\hat{\theta}(t)=\hat{\theta}(t-1)+P(t) \varphi^{T}\left(y(t)-\varphi^{T}(t) \hat{\theta}(t-1)\right) \cdots .$.
$P(t)=\frac{1}{\lambda}\left(P(t-1)-\frac{P(t-1) \varphi(t) \varphi^{T}(t) P(t-1)}{\lambda+\varphi(t) P(t-1) \varphi^{T}(t)}\right) \ldots$.

\section{Hasil dan Pembahasan}

Estimasi parameter model dengan metode RLS berbasis forgetting factor disimulasikan dengan menggunakan periode pencuplikan $\left(T_{s}\right)$ 0,4 detik; 0,35 detik; 0,3 detik; 0,25 detik dan 0,2 detik, inisialisasi awal matrik kovarian $\mathrm{P}(0)=\alpha \mathrm{l}$, dengan I adalah matrik identitas berdimensi $8 \times 8$ dan $\alpha=10^{8}$, inisialisasi vektor parameter $\hat{\theta}(t)=0$, dengan jumlah data setiap kondisi nilai radius $(\mathrm{N})$ $=50$ data, jumlah putaran selama proses sistem transportasi web material $=884$ putaran, nilai forgetting factor yang disimulasikan $\lambda=1 ; 0,99 ; 0,98 ; 0,97 ; 0.96 ; 0,95$. Hasil simulasi ditunjukkan oleh Tabel 2 serta Gambar 4 dan Gambar 5 dengan $T s=0,3$ detik. Konvergensi hasil estimasi parameter model ditentukan berdasarkan nilai mean square error (MSE) pada daerah $2 \times 10^{-5} \leq$ MSE $\leq 3 \times 10^{-5}$.

Tabel 2. Hasil Estimasi Parameter Model

\begin{tabular}{|c|c|c|c|c|c|c|}
\hline $\mathrm{T}_{\mathrm{s}}$ & \multicolumn{7}{|c|}{ Forgetting Factor / MSE } \\
\hline (detik) & $\lambda=1$ & $\lambda=0,99$ & $\lambda=0,98$ & $\lambda=0,97$ & $\lambda=0,96$ & $\lambda=0,95$ \\
\hline 0,4 & $3,3 \mathrm{e}+1$ & $2,1 \mathrm{e}-2$ & $3,0 \mathrm{e}-3$ & $1,3 \mathrm{e}-3$ & $1,8 \mathrm{e}-4$ & $2,5 \mathrm{e}-5$ \\
\hline 0,35 & $4,1 \mathrm{e}+1$ & $2,5 \mathrm{e}-2$ & $1,0 \mathrm{e}-2$ & $6,9 \mathrm{e}-4$ & $1,9 \mathrm{e}-4$ & $2,3 \mathrm{e}-5$ \\
\hline 0,3 & $4,3 \mathrm{e}+2$ & $8,2 \mathrm{e}-3$ & $6,7 \mathrm{e}-3$ & $3,1 \mathrm{e}-4$ & $5,9 \mathrm{e}-4$ & $2,6 \mathrm{e}-5$ \\
\hline 0,25 & $1,3 \mathrm{e}+1$ & $3,1 \mathrm{e}-2$ & $9,9 \mathrm{e}-4$ & $7,8 \mathrm{e}-4$ & $5,9 \mathrm{e}-5$ & $2,4 \mathrm{e}-5$ \\
\hline 0,2 & $3,8 \mathrm{e}+0$ & $1,8 \mathrm{e}-2$ & $3,2 \mathrm{e}-4$ & $1,9 \mathrm{e}-4$ & $9,3 \mathrm{e}-5$ & $2,4 \mathrm{e}-5$ \\
\hline
\end{tabular}

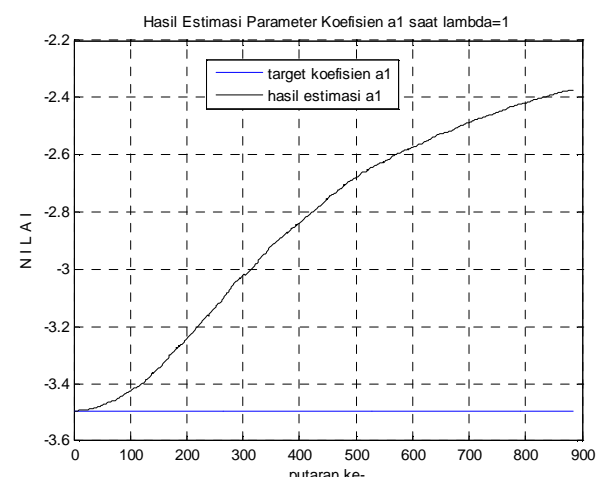

Gambar 4a. Hasil Estimasi Parameter $a_{1} \lambda=1$ 


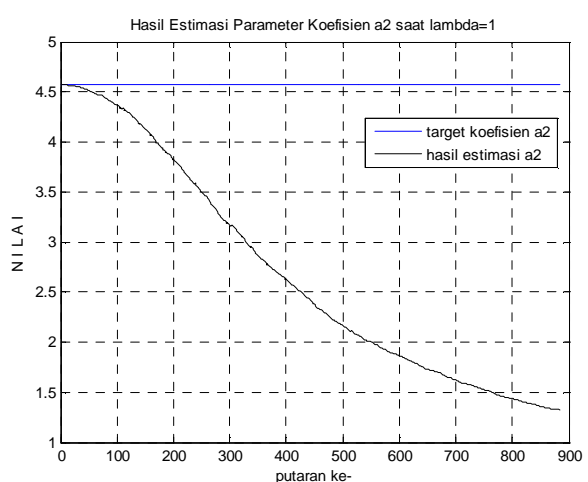

Gambar 4b. Hasil Estimasi Parameter $\mathrm{a}_{2}, \lambda=1$

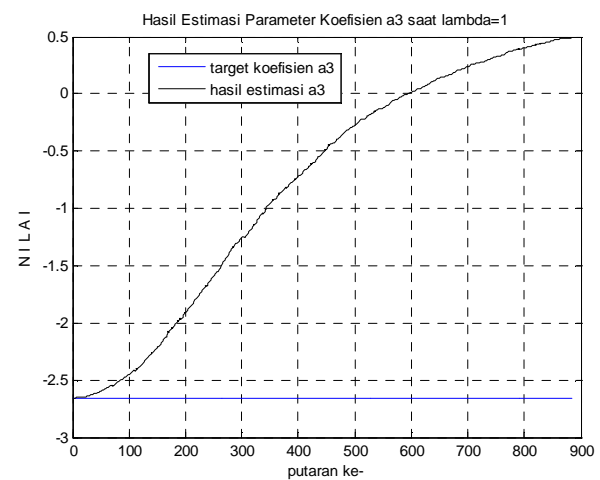

Gambar 4c. Hasil Estimasi Parameter $a_{3}, \lambda=1$

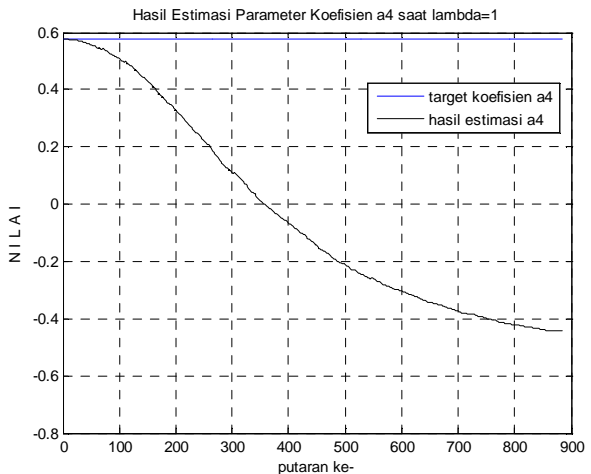

Gambar 4d. Hasil Estimasi Parameter $\mathrm{a}_{4}, \lambda=1$

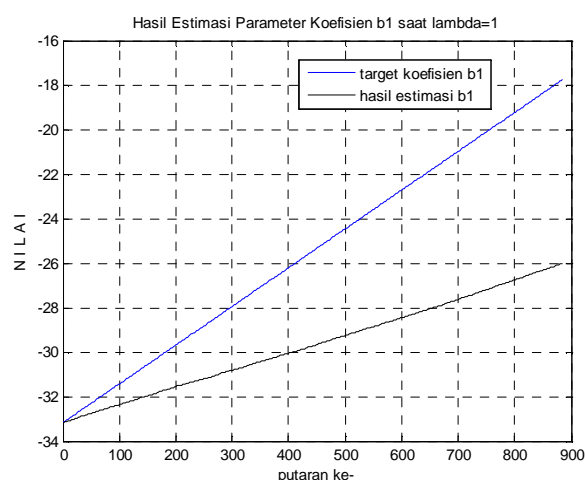

Gambar 4e. Hasil Estimasi Parameter $b_{1} \lambda=1$ 


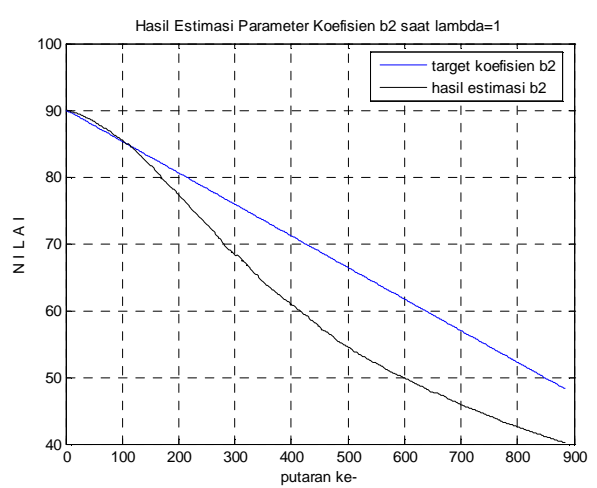

Gambar 4f. Hasil Estimasi Parameter $b_{2}, \lambda=1$

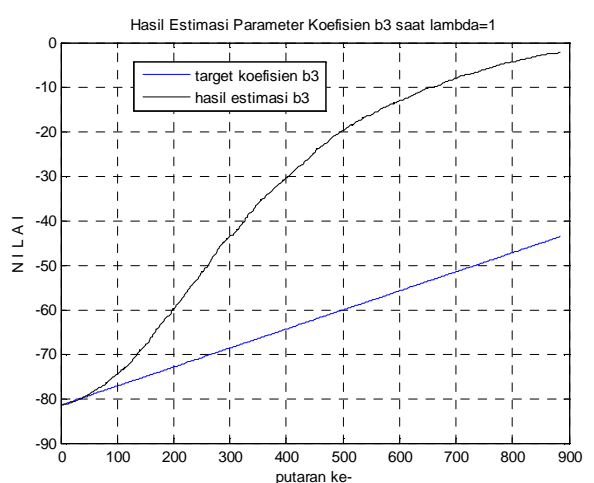

Gambar 4g. Hasil Estimasi Parameter $b_{3}, \lambda=1$

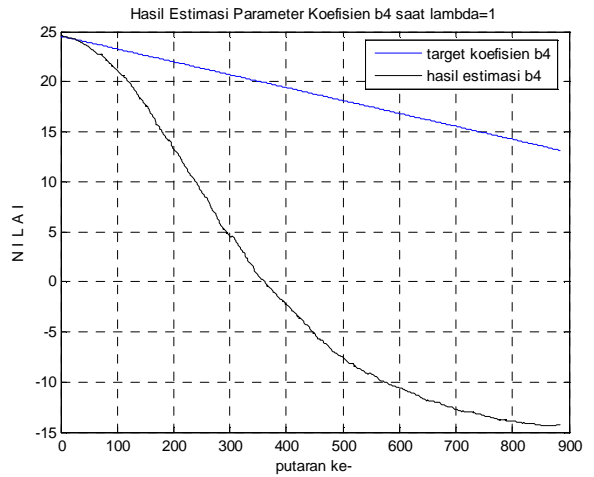

Gambar 4h. Hasil Estimasi Parameter $b_{4}, \lambda=1$

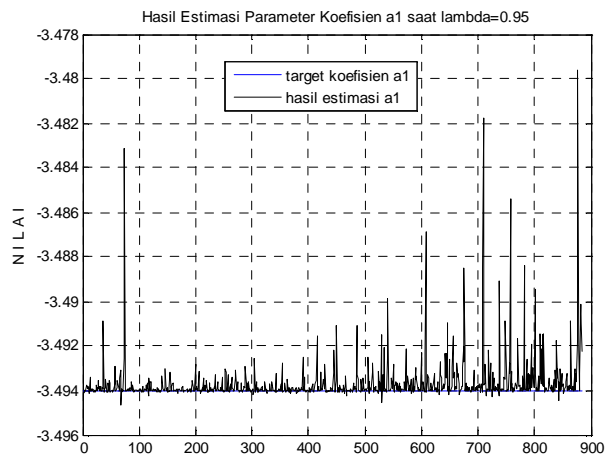

Gambar 5a. Hasil Estimanasi Parameter $\mathrm{a}_{1} \quad \lambda=0,95$ 


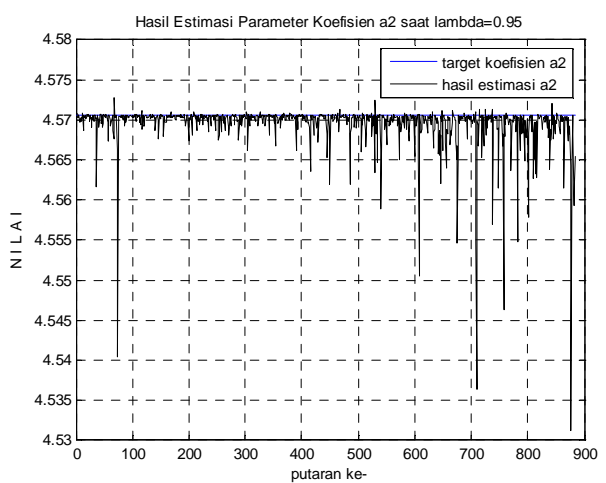

Gambar 5b. Hasil Estimasi Parameter $\mathrm{a}_{2}, \lambda=0,95$

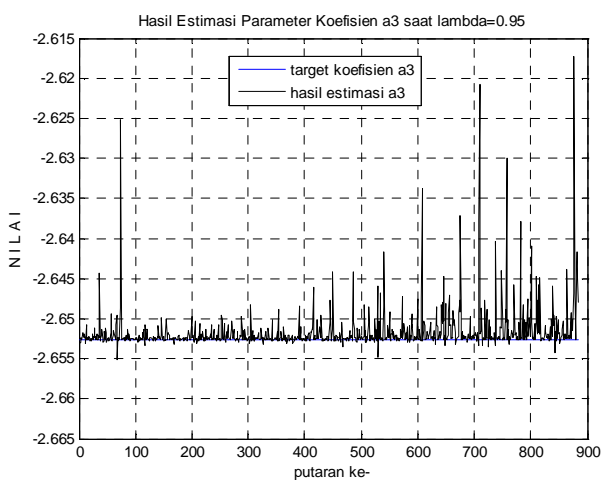

Gambar 5c. Hasil Estimasi Parameter $\mathrm{a}_{3}, \lambda=0,95$

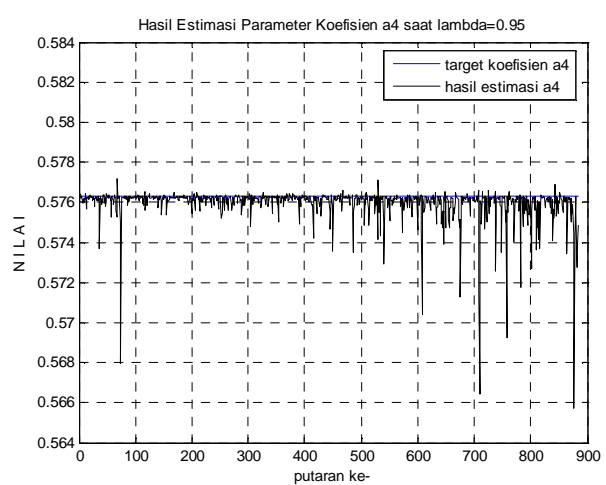

Gambar 5d. Hasil Estimasi Parameter $\mathrm{a}_{4}, \lambda=0,95$

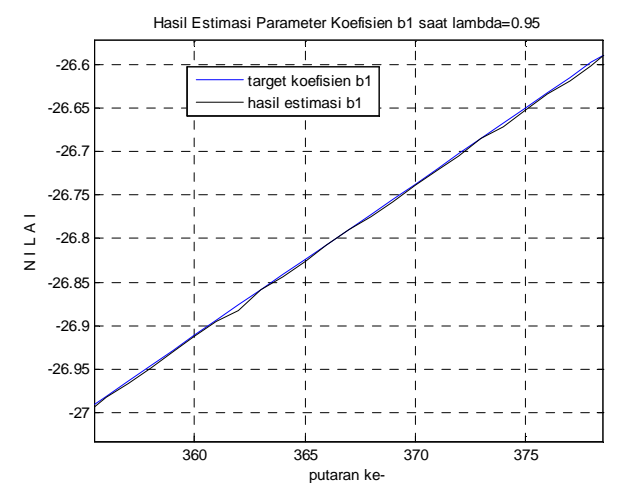

Gambar 5e. Hasil Estimasi Parameter $b_{1} \lambda=0,95$ 


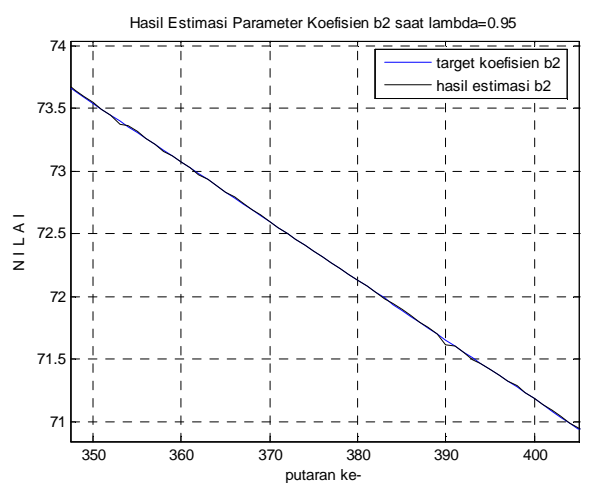

Gambar 5f. Hasil Estimasi Parameter $b_{2}, \lambda=0,95$

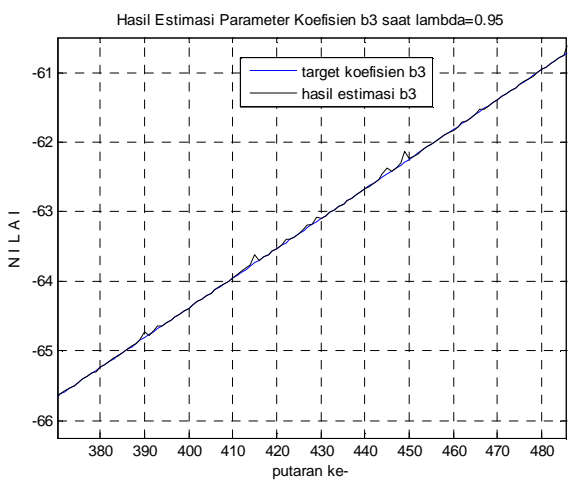

Gambar 5g. Hasil Estimasi Parameter $b_{3}, \lambda=0,95$

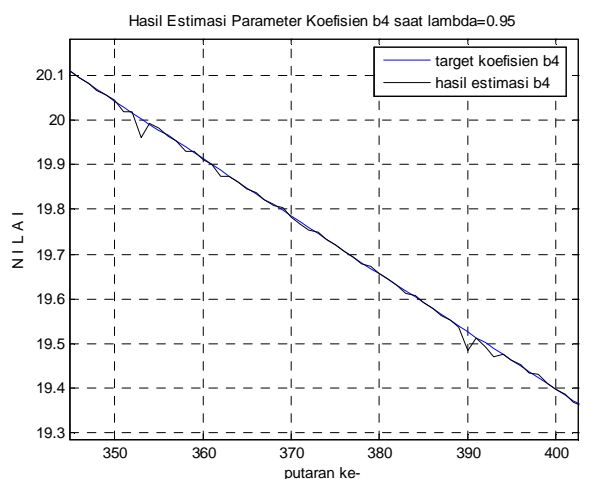

Gambar 5h. Hasil Estimasi Parameter $b_{4}, \lambda=0,95$

Dari hasil estimasi parameter model yang ditunjukkan Tabel 2 terlihat dengan periode pencuplikan (Ts) 0,4 detik; 0,35 detik; 0,3 detik; 0,25 detik dan 0,2 detik dan perubahan nilai forgetting factor $1 \leq \lambda \leq 0,95$ terlihat bahwa estimasi parameter akan konvergen pada nilai MSE sebesar $2 \times 10^{-5} \leq \mathrm{MSE} \leq 3 \times 10^{-5}$ pada nilai forgetting factor $\lambda=0,95$ serta terlihat bahwa nilai MSE tidak sensitif terhadap periode pencuplikan. Hal ini juga dibuktikan dari Gambar $4 a$ sampai $4 \mathrm{~h}$ untuk nilai forgetting factor $\lambda=1$ hasil estimasi parameter dan target parameter saling menjauh yang menunjukkan hasil yang tidak konvergen, sedangkan Gambar 5a sampai Gambar 5h menunjukkan untuk nilai forgetting factor $\lambda=0,95$ konvergen antara hasil estimasi parameter dan target parameter. 
3. Kesimpulan

Estimasi parameter model dengan metode diskritisasi $\mathrm{ZOH}$ konvergen dengan nilai forgetting factor $\lambda=0,95$ dengan nilai MSE sebesar $2 \times 10^{-5} \leq \mathrm{MSE} \leq 3 \times 10^{-5}$ yang tidak sensitif terhadap perubahan periode pencuplikan 0,4 detik; 0,35 detik; 0,3 detik; 0,25 detik dan 0,2 detik.

\section{Daftar Pustaka}

B. Carisson, Uppala Universitet Institutionen for Informationsteknologi, February 11, 2009

C. Bonivento, Andea Paoli, Lorenzo Marconi, Department of Electronic, Systems and Computer Science, University of Bologna.

H. Koc, Dominique Knittel, Michel de Mathelin, Gabriel Abba, IEEE Transactions on Control Systems Technology, Vol. 10, N0. 2, March 2002.

K. Ogata, Edi Leksono, Erlangga 1995.

P.R.Pagilla, Member IEEE, Nilesh B. Siraskar, Ramamurthy V. Dwivedula, IEEE Transactions on Control Systems Technology, Vol. 15, N0. 1, January 2007.

T. Bastogne, M. Thomassin, J. Masse, Control Engineering Practice, 2006.

Y.Hou, Ph.D Thesis, Cleveland State University, August 2001. 